\title{
We Have to Create A New and Successful Way to Retain Nurses in The Future: How Can We Further Improve Nurses' Commitment to Their Profession?
}

Miho Satoh

Department of Nursing, Tokyo Healthcare University, Japan

Article Details
Article Type: Commentary Article
Received date: $10^{\text {th }}$ August, 2016
Accepted date: $17^{\text {th }}$ Oct, 2016
Published date: $24^{\text {th }}$ Oct, 2016

"Corresponding Author: Miho Satoh, Department of Nursing, Tokyo Healthcare University, 2-5-1 Higashigaoka, Meguro-ku, Tokyo, 152-8558, Japan. E-mail: miho.sth@gmail.com

Citation: Satoh M (2016) We Have to Create A New and Successful Way to Retain Nurses in the Future: How Can we Further Improve Nurses' Commitment to Their Profession? J Comp Nurs Res Care 1: 102. doi: http://dx.doi.org/jenrc/2016/102.

Copyright: (C2016, This is an open-access article distributed under the terms of the Creative Commons Attribution License 4.0, which permits unrestricted use, distribution, and reproduction in any medium, provided the original author and source are credited.

Keywords: nursing, occupational commitment, professional turnover, intention to stay

In the industrial psychology research area, commitment to work has been argued to be a common construct of the psychological attitude to work. Working people have always been likely to commit to their organization. However, as an occupation is a significant aspect of people's lives, commitment to an occupation has recently been attracting a great deal of interest.This trend is no exception in nursing. Occupational commitment is defined as "a psychological link between a person and his or her occupation that is based on an affective reaction to that occupation"[1], or "a commitment to professional objectives, values, beliefs, and willingness to continue in one's profession" [2]. Occupational commitment is related to job attitude or work-related behavior. In particular, occupational commitment is proposed to be a strong predictor of professional turnover intention and motivation for entering a profession[3,4]. When nurse managers discuss nurse turnover or consider an efficient way to recruit and retain nurses, occupational commitment could be the key to success.

Ensuring adequate nursing personnel is a global concern.In the US and European countries, $5 \%$ to $49 \%$ of nurses have thought aboutleaving the profession [5].A survey by the Japanese Nursing Association [6] reported that $58.1 \%$ of nurses wanted to continue working as a nurse.However, the survey found that $32.0 \%$ showed a lower attachment to the nursing profession [6]. Decreasing commitment to nursing and an increase in the professional turnover rate among nurses has had serious effects on the healthcare system. An insufficient nursing workforce and nursing shortagecould lead to a decreasein the quality and safety of patient care $[5,7]$.

Ensuring adequate nursing personnel is a global concern. In the US and European countries, $5 \%$ to $49 \%$ of nurses have thought about leaving the profession [5]. A survey by the Japanese Nursing Association [6] reported that $58.1 \%$ of nurses wanted to continue working as a nurse. However, the survey found that $32.0 \%$ showed a lower attachment to the nursing profession [6]. Decreasing commitment to nursing and an increase in the professional turnover rate among nurses has had serious effects on the healthcare system. An insufficient nursing workforce and nursing shortage could lead to a decreasein the quality and safety of patient care $[5,7]$.

Healthcare settings make an effort to prevent nurse turnover from their organization and to secure nursing personnel within their organizations. These attempts are highly important from the standpoint of the organization's human resources management. However, professional turnover should be considered a more critical issue than organizational turnover. As shown in the survey reports by various countries and Japan that were previously mentioned [5-7], there is an increasing number of inactive nurses, and we now face the serious fact that the total number of nurses is decreasing steadily internationally. Nursing professional turnover leads to a loss of tacit knowledge, expert skills, and extensive nursing experience, and it is costly to the healthcare system. Thus, the healthcare system could suffer fatal damage.Most of the measures that prevent nurse turnoveraim at promoting organizational socialization for new nurses or enhancingthe organizational structural and cultural support for juggling work and their personal life. These measures are completelytothe organization's advantage.Policies that intend to provide support for those in the nursing profession are needed by whole healthcare systems.

As mentioned above, many research studies have demonstrated that occupational commitment is a significant factor affecting the intention to leave or to continue in the nursing profession.Although these studies stressed the importance ofdeveloping occupational commitment for motivating the intention to stay in nursing [8], few studies have been conducted into the strategiesor interventionsthat improve occupational commitment among nurses.

Resilience, self-esteem, and psychological capital (defined as "a positive state of mind exhibited during the growth and development of an individual" [9]), which are personal internal resources, have also gained attentionas key factors in overcoming the adverse effects of job stress and reducing turnover intention[10,11]. Exercises and strategies for nurses to develop and maintain their personal resilience, self-efficacy, and psychological capital are implemented in the workplace.In the same manner, it is an urgent issue that intervention programs are constructed to develop occupational commitment. With this view in mind, surveys need to be conducted to clarify the determinants of occupational commitment.

\section{Disclosure}

The author meets the ICMJE criteria for authorship credit (www. icmje.org/ethi-cal_1author.html), as follows: (1) substantial contributions to the conception and design, acquisition of data, or analysis and interpretation of data; (2) drafting the article or revising 
it critically for important intellectual content; and (3) final approval of the version to be published.

Conflicts of Interest: The author declares that there are no conflicts of interest.

\section{References}

1. Lee K, Carswell JJ, Allen NJ (2000) A meta-analytic review of occupational commitment: Relations with person- and workrelated variables. J Appl Psychol 85: 799-811.

2. Teng CI, Dai YT, Shyu YI, Wong MK,Chu TL, et al. (2009) Professional commitment, patient safety, and patient-perceived care quality. J Nurs Scholarsh 41:301-309.

3. Flinkman M, Laine M, Leino-Kilpi H, Hasselhorn HM, Salantera S (2008) Explaining young registered Finnish nurses' intention to leave the profession: A questionnaire survey. Int $\mathrm{J}$ Nurs Stud 45: 727-739.

4. Gambino KM (2010) Motivation for entry, occupational commitment and intent to remain: A survey regarding registered nurse retention. J Adv Nurs 66: 2532-2541.

5. Aiken LH, Sermeus W, Van den Heede K, Sloane DM, Busse R, et al. (2012) Patient safety, satisfaction, and quality of hospital care: Cross sectional surveys of nurses and patients in 12 countries in Europe and the United States. BMJ344: e1717.

6. Japanese Nursing Association (2015) Survey on the Demand and Supply of Hospital Nurses 2014.

7. Aiken L, Sloane DM, Bruyneel L, Van den Heede K, Griffiths P, et al.(2014) Nurse staffing and education and hospital mortality in nine European countries: A retrospective observational study. Lancet 383: 1824-1830.

8. Satoh M, Watanabe I, Asakura K (2016) Occupational commitment and job satisfaction mediate effort-reward imbalance and the intention to continue nursing. Jpn J Nurs Sci.

9. Luthans F, Youssef CM (2004) Human, social, and now positive psychological capital management: Investing in people for competitive advantage. Organ Dyn 33: 143-160.

10. McDonald G, Jackson D, Vickers MH, Wilkes L (2016) Surviving workplace adversity: A qualitative study of nurses and midwives and their strategies to increase personal resilience. J Nurs Manag 24: 123-131.

11. PineauStam LM, Spence Laschinger HK, Regan S, Wong CA (2015) The influence of personal and workplace resources on new graduate nurses' job satisfaction. J Nurs Manag 23:190199. 